\title{
AMYLOIDOSIS OF BONE
}

\author{
Report of Two Cases
}

\section{U. Axelsson, A. Hallén and A. Rausing, Malmö, Sweden}

From the Department of Internal Medicine and the Department of Pathology, Malmö General Hospital

Amyloid deposits in the bone marrow are rare. In generalised vascular amyloidosis the vessels of the bone marrow are sometimes involved, but the parenchyma is rarely affected in amyloidosis secondary to chronic disease such as rheumatoid arthritis or chronic osteomyelitis. In patients with amyloid in the bone marrow, destruction sometimes dominates the clinical picture and then the amyloidosis may be difficult to diagnose.

Apart from its occurrence as an accompaniment of vascular amyloidosis, three types of amyloidosis of the bone marrow have been described: 1) diffuse amyloidosis, with or without co-existing local tumour-like masses; 2) amyloidosis associated with malignant tumours; and 3) local tumour-like accumulations of amyloid in the absence of general amyloidosis.

General amyloidosis with diffuse involvement of the bone marrow in the absence of any demonstrable primary disease seems to have been described first by Gerber (1934). When Koletsky and Stecher (1939) reviewed the literature on primary amyloidosis they did not mention the occurrence of diffuse bone marrow amyloidosis in any further case. Their own patient had only local involvement of the skeleton with spontaneous fracture of the femur. "Primary" amyloidosis can no longer be regarded as extremely rare (Hällén and Rudin 1966), but amyloid deposits in the bone marrow are very uncommon. The bone marrow was examined histologically by Hällén and Rudin in eighteen of their forty-six cases but in none was amyloid found.

When amyloidosis occurs in association with malignant disease it usually accompanies myelomatosis but sometimes occurs with renal cancer or medullary thyroid cancer. In myelomatosis amyloid is rarely found in the myelomatous foci. Myelomatosis with massive tumour-like deposits of amyloid has, however, often been described (Wallgren 1920; Freund 1930; Rosenblum and Kirschbaum 1936; Dünner 1946; Schinz, Baensch, Friedl and Uehlinger 1952; Pende and Chiarioni 1953; Fadell and Morris 1964; Lowell 1967). Sometimes the amyloid occurs in large amounts and then replaces the myeloma tissue. The histological examination of biopsy specimens and of sternal marrow as well as radiographic examination may then give false results. Dahlin and Dockerty (1950) in a series of sixty-six biopsy specimens of myeloma found fourteen with local amyloid deposits. Twelve of the patients had tumours that had broken through the affected bone and spread in the soft tissues. This is a high figure compared with that found at necropsy.

The third form, amyloid tumour in the absence of known malignant disease, has often been reported in the older literature (Hedrén 1907, Wolpert 1920, Mandl 1924, von Bonsdorff 1933). Multiple manifestations have also been described and then called "metastasising amyloid tumours". Wolpert (1920) published a personal case and gave a survey of the previous literature, mainly of amyloid tumours of the soft tissues. He concluded that most cases are of this type and that the occasionally very cellular tissue in which the amyloid masses are embedded is reactive granulation tissue. Only one amyloid tumour combined with a malignant tumour (lymphosarcoma) was accepted as such. It was believed to have originated in the mediastinum and to have metastasised to the thyroid gland and other sites. (This could have been a misdiagnosed medullary thyroid cancer.) Judging from the now known great variability of myeloma it is possible that other cases on record may in reality have been multiple myelomata. Bürgi (1937) described an amyloid tumour of the skull following repeated injuries. Necropsy revealed no amyloid tissue elsewhere and Bürgi regarded the lesion as a true amyloid 
tumour, but the contiguous tissue contained numerous plasma cells. Bürgi referred to nine cases from the literature and thought that all of them were examples of benign tumour-like deposits of amyloid. Cases with local amyloidosis and Bence-Jones protein in the urine without radiologically or histologically demonstrable myeloma have been reported (Michelson and Lynch 1934).

Two cases of different forms of amyloid deposits will be described. We believe them to be of biologically different character, not resembling one another pathologically, except that both involved bone. Both cases were clinically, radiologically and histologically elusive.

\section{CASE REPORTS}

Case 1-A man born in 1895 had been treated at the department of orthopaedic surgery from 1949 to 1958 for back pain. During these years radiographic examination revealed progressive vertebral compression suggesting osteoporosis (Figs. 1 and 2). The erythrocyte sedimentation

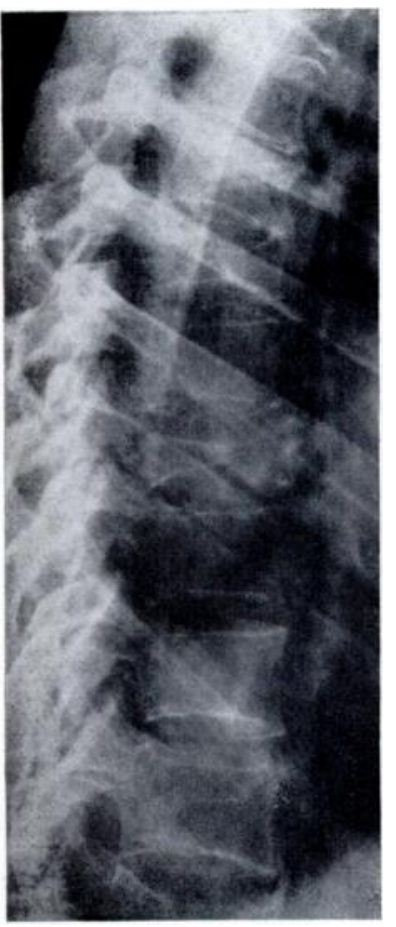

FIG. 1

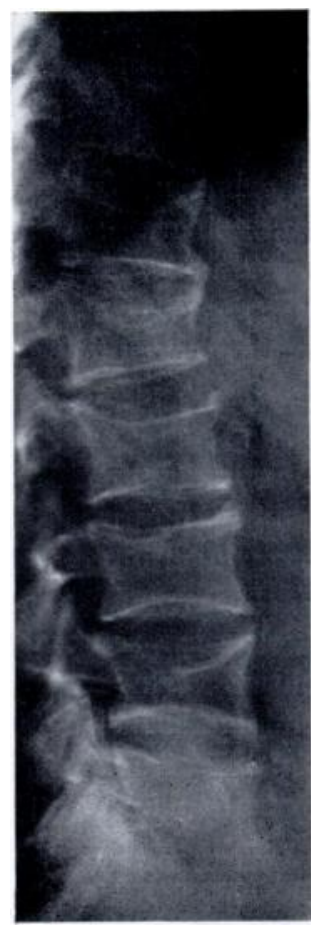

FIG. 2

Case 1. Figure 1-Lateral radiograph of thoracic spine showing compression of several thoracic vertebrae suggestive of osteoporosis. Figure 2-Lateral radiograph of lumbar spine showing similar changes. rate remained at about 60 millimetres in the first hour from the beginning. There was occasional proteinuria. Haemoglobin gradually fell to 10 grammes/100 millilitres. In 1958 malignant disease was suspected but could not be confirmed. Serum calcium and alkaline phosphatase values were normal. Protein electrophoresis showed only an increase of the $\alpha_{2}$-fraction.

The patient was first seen at the department of internal medicine in 1959. The liver was then enlarged, but needle biopsy failed to reveal any abnormality. Staining for amyloid was not done. The result of the bromsulphthalein test was normal. Serum gamma globulin was not increased. Paper electrophoresis showed as before an increase of the $\alpha_{2}$-fraction only. Serological studies were normal. Haemoglobin was 10.4 grammes/100 millilitres. Erythrocytes were 3.6 million/cubic millimetre. There was no proteinuria. The positive findings, vertebral compression, hepatomegaly and anaemia, were not sufficient to allow a diagnosis to be made.

Despite persistent back pain and fatigue he continued his work until his retirement in

1962. In 1965 the patient was again examined in the department of internal medicine. The erythrocyte sedimentation rate was then 140 millimetres in the first hour. Electrophoresis showed a marked increase of the $\alpha_{2}$-fraction. There was no M-component (discrete globulin band) in the serum or urine protein. Serum cholesterol was 230 milligrams/100 millilitres, urine protein 5 milligrams/litre and serum creatinine 2.9 milligrams/100 millilitres. Renal function tests using radioisotopes showed poor uptake on both sides. The liver was still enlarged. Radiographs of the bones showed the same picture as before. The alkaline phosphatase had increased to 16 units. Hydroxyproline in the urine was normal. Radiographic examination of the heart showed a relative volume of 700 millilitres/square metre of body surface. An electrocardiograph revealed non-specific changes over the left ventricle. Systolic hypertension was found. The 
xylose tolerance test was pathological $-1 \cdot 2$ grammes (normal value $>4$ grammes). The examination thus showed not only the changes found previously but also enlargement of the heart and signs of malabsorption.

In 1966 oedema of the legs and pleural effusion supervened. The patient felt weaker and lost weight. When last admitted to the department of internal medicine the patient was still anaemic. The erythrocyte sedimentation rate was raised, there was proteinuria and the $\alpha_{2}$-fraction was still increased. Serum creatinine was 4 milligrams $/ 100$ millilitres. There was hyperkalaemia. The xylose test was 0.3 grammes. Faecal fat was 23 grammes in twenty-four hours. Schilling's test was abnormal, being 1.7 per cent with no increase after administration of intrinsic factor. The suspicion of amyloid disease was aroused when the patient developed a small haemorrhage in the lower eyelid. There was no amyloid in a rectal biopsy specimen. The patient died of uraemia.

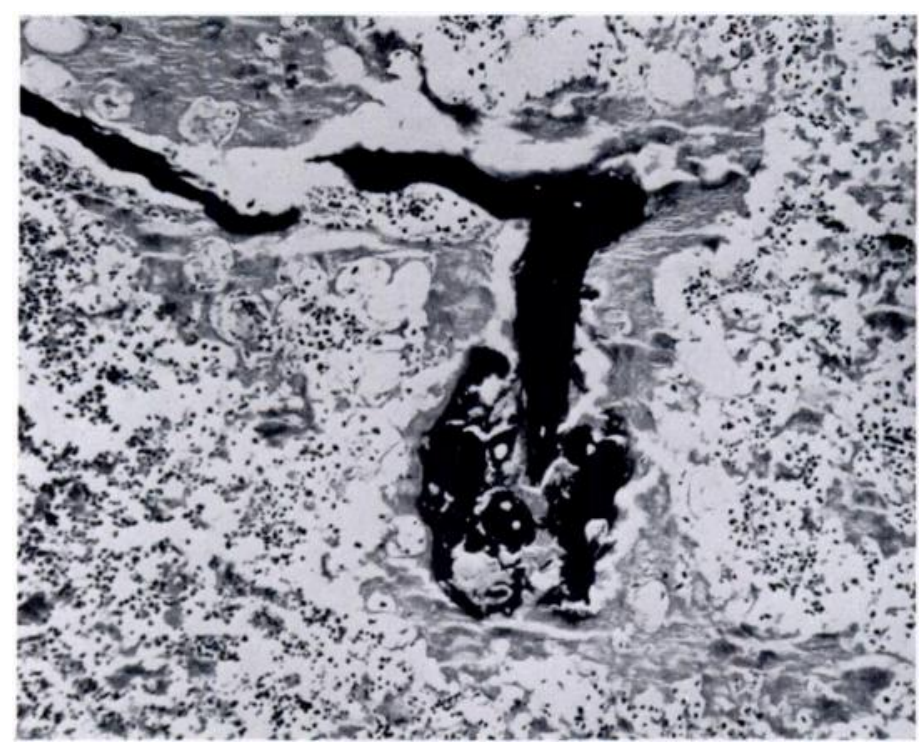

Fig. 3

Case 1-Histological section showing amyloid deposits in vertebral bone marrow replacing bony trabeculae and blood-forming parenchyma. (Van Gieson, × 130.)

Necropsy findings-The marrow of the vertebrae was strikingly soft and yellowish-red in colour. Several of the vertebrae showed compression fractures. Histological section showed the marrow from vertebrae and the femur to contain massive deposits of amyloid. The trabeculae were reduced in number and thickness. Osteoclasts were not particularly abundant. The amyloid deposits were not arranged in any special pattern relative to bone structures and were seen in large and small irregular foci surrounding small areas of preserved erythropoietic parencyhma and sometimes enclosing remnants of eroded bone trabeculae. In some areas there were somewhat larger amyloid conglomerates. Occasional multinuclear foreign-body giant cells were seen. Better preserved parts contained normal blood-forming parenchyma. There was no increase of plasma cells (Fig. 3). The homogeneous amyloid masses in the bone marrow and in other organs stained weakly metachromatically with methyl violet. Lymph nodes in the mediastinum and para-aortic region were enlarged. Histological sections of a para-aortic lymph node showed large amyloid masses completely replacing the normal structure. Here, too, scattered giant cells were situated around amyloid masses and fairly numerous plasma cells of typical morphological appearance. The spleen was moderately enlarged and contained amyloid mainly in the sinusoids of the red pulp, and in small amounts in the lymphatic tissue. Scattered multinuclear giant cells were found round the amyloid deposits, but plasma cells were not numerous in the spleen.

The liver was markedly enlarged and histologically the walls of its sinusoids contained massive deposits of amyloid, which in some areas had formed conglomerates and replaced the liver cells. 
Amyloid was also seen in the portal zones. The parenchyma of the adrenals exhibited moderate amyloid degeneration.

Amyloid deposits were found in the glomeruli and vessels of the kidney and to some extent also in the stroma. The kidney also showed signs of acute pyelonephritis.

Sections from the stomach, the jejunum and the colon were examined. No amyloid was found in the mucosa or blood vessels. Neither did the mesentery or the lymph nodes contain any amyloid and only traces of amyloid were seen in their blood vessels.

There was widespread, subcutaneous oedema and fluid in the serous cavities. The heart was enlarged but showed no sign of amyloidosis. All the parathyroid glands were slightly hyperplastic, but their histological picture was normal.

Case 2-The patient, a man born in 1907, had generally felt well until 1960 when he was admitted with a spontaneous fracture of the left humerus. Radiographs showed cystic changes. Biopsy specimens of the cyst in 1961 and 1962 were interpreted as a giant-cell tumour. In 1963

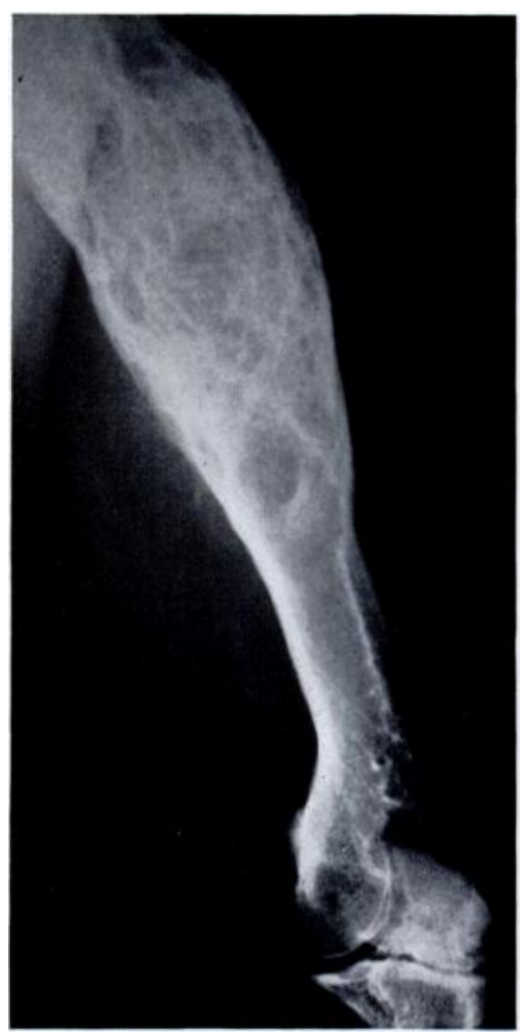

FIG. 4

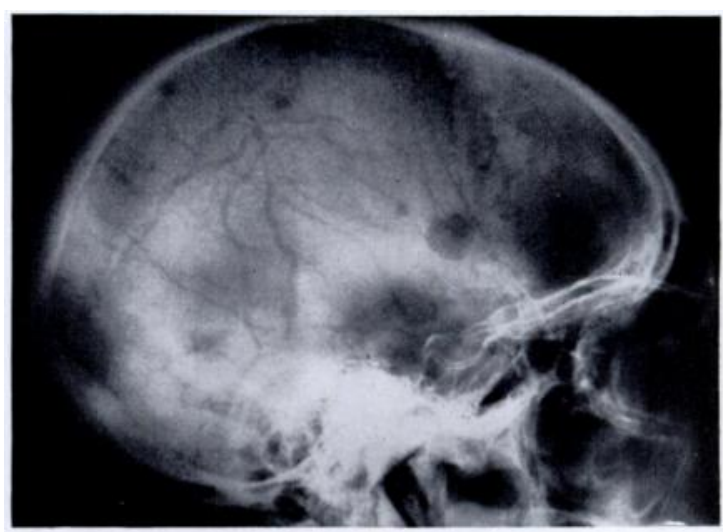

FIG. 5

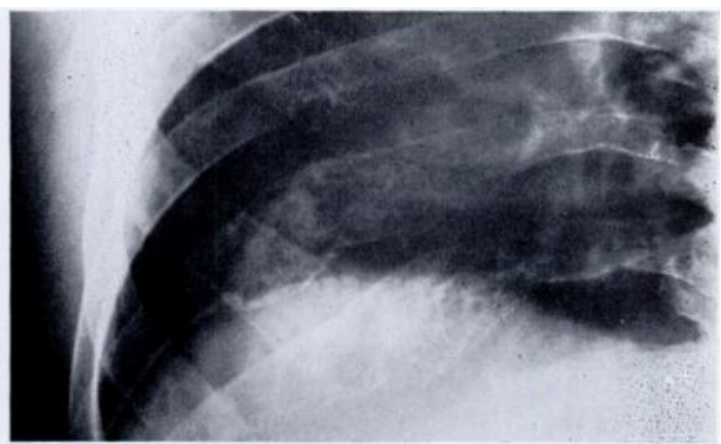

Fig. 6

Case 2. Figure 4-Radiograph of the left humerus showing diaphysial swelling, rarefaction and osteosclerotic septa. Figure 5-Radiograph of the skull showing the second type of lesion: multiple osteolytic foci without surrounding bony reaction. Figure 6-Radiograph of the rib-cage showing lesions similar to that in Figure 4.

radiation treatment was given to the upper arm. In that year the lymph nodes of the left axilla began to enlarge. Biopsy of the lymph nodes revealed giant cells and an increase in the number of plasma cells. Radiographs of the skeleton then showed an osteolytic focus in the fourth cervical vertebra and the patient was given radiation therapy. In 1964 he was treated with cyclophosphamide.

In 1966 he complained of increasing pain in the left upper arm, and in the back and pelvis. He was examined at the department of internal medicine, Säffle Hospital. The patient was found to be in a good general condition apart from severe wasting of the right thenar and 
hypothenar eminences. Repeated alkaline phosphatase estimations varied between 7 and 14 units. Paper protein electrophoresis of the urine showed two M-components.

In January 1967 the patient was admitted to the department of internal medicine of Malmö General Hospital. Examination showed atrophy of the right hand and a firm conglomerate of lymph nodes in the left axilla. Investigations showed a haemoglobin level of 10 grammes/100 millilitres, with an erythrocyte count of 3 million/cubic millimetre. White cell and platelet counts were normal. Serum creatinine was 1.2 to 1.4 milligrams $/ 100$ millilitres. The alkaline

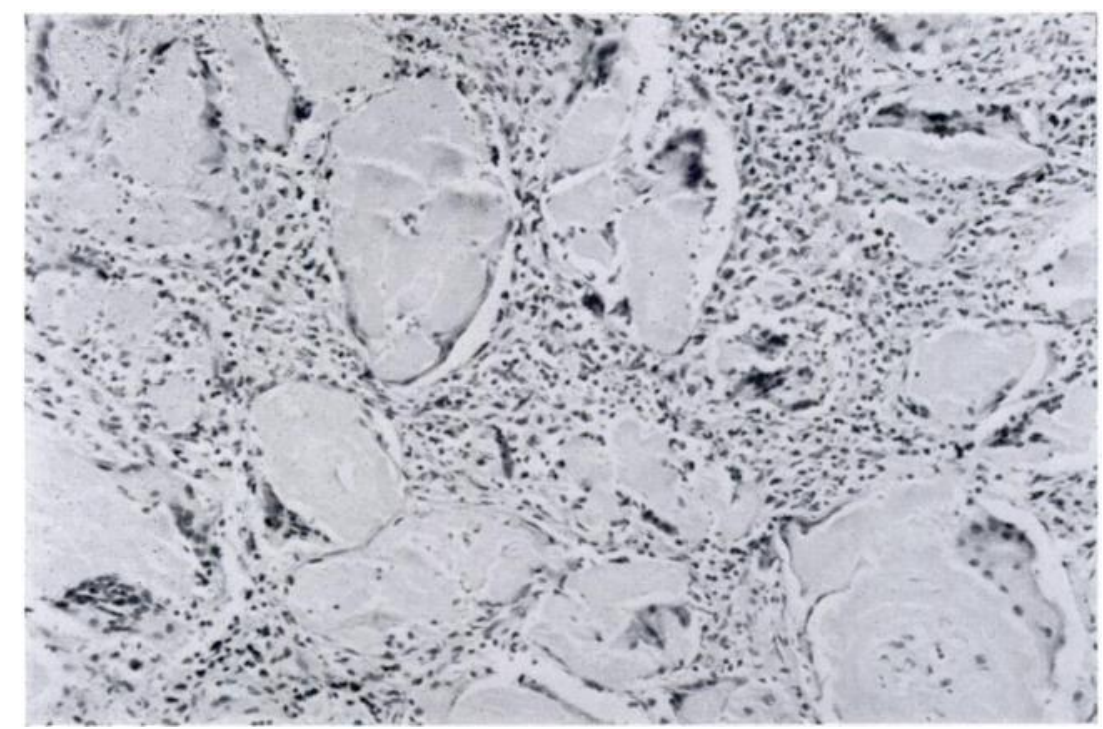

Fig. 7

Case 2-Histological section of a tumour in the frontal bone showing amyloid deposits surrounded by giant cells and myelomatous tissue. (Haematoxylin and eosin, $\times 170$.)

phosphatase was 8 units and the serum calcium level normal. Serum electrophoresis showed a low total protein with decreased albumin and slightly increased $\alpha_{2}$-fraction as well as a slightly decreased gamma globulin level. No M-component was demonstrable in the serum. Urine electrophoresis revealed two abnormal components. One of these was a light chain of type $\mathrm{K}$, the other a component of low molecular weight belonging to the $\mathrm{K}$ group. The total urine protein was 0.6 milligram $/ 100$ millilitres. A specimen containing only a few multinuclear giant cells was obtained by sternal puncture. Spinal puncture revealed that the bone marrow was rich in cells, of which 3.6 per cent were plasma cells.

Radiographs showed two types of lesion. The skull had multiple osteolytic foci without any marginal reaction (Fig. 5). Lesions of the same type were found in several vertebrae, in the left femur and in both tibiae. A large osteolytic defect was seen in the neck of the right radius. The left humerus had a fifteen-centimetre-long area in which the diaphysis was abnormally wide and the bone rarefied with osteosclerotic septa (Fig. 4). Similar pictures with rarefied bone substance and septa were seen in several ribs (Fig. 6). Treatment with Alkeran was started. When last seen in February 1969 the patient was well.

Histological findings-The tumour of the left humerus was examined histologically for the first time in 1961. The material obtained for examination consisted of small pieces of brittle tissue with tiny bone fragments. The picture was dominated by numerous multinuclear giant cells and was interpreted as a giant-cell tumour. The stroma contained amorphous substance which did not stain for amyloid.

The tumour was again examined histologically in 1962. The patient then had a massive recurrence. The histological picture was the same as before. In 1963 a large lymph node was removed from the left axilla. It was examined at another department of pathology and was found to contain abundant 
hyaline masses, which now stained positively for amyloid. It was surrounded by numerous syncytial giant cells. The lymph node contained also accumulations of atypical plasma cells, and myeloma was suspected.

In January 1967 a biopsy was obtained from an osteolytic focus in the forehead (Fig. 7). The specimen consisted mainly of round or oval amyloid masses. In some areas the amyloid foci were compact and showed a tendency to concentric layer formation. Some of them showed a small central blood vessel lumen. The amyloid masses were surrounded by numerous multinuclear giant cells. In some areas the foci coalesced to form acellular amyloid masses; in others they were embedded in highly cellular tissue built of fairly large cells with abundant homogeneous cytoplasm and round or oval nuclei with a coarse chromatin network. In many of the cells the nucleoli were well defined. They were pyroninophilic. Although the cytoplasm was usually only diffusely outlined and the cells were arranged in more or less reticular formations, they showed typical features of plasma cells and the diagnosis of plasmacytoma with massive amyloid deposits was now made. The tissue also contained lymphocytes and numerous plasma cells of typical morphological appearance. A biopsy of a lymph node from the left axilla showed the same picture. The amyloid stained faintly positive with methyl violet but with an intensity varying from one part of the preparation to another.

\section{DISCUSSION}

The first patient had been ill for sixteen years. His disease was dominated by progressive compression of the cervical and lumbar vertebrae. Throughout this period the erythrocyte sedimentation rate was high, the protein $\alpha_{2}$-fractions were increased, but the gamma globulin was normal and no Bence-Jones protein was found in the urine. Such a clinical picture suggested malignant disease. The development of hepatomegaly, however, obscured the picture, especially since histological examination of a liver biopsy specimen had revealed nothing abnormal. It was not until after renal insufficiency and malabsorption had occurred that amyloidosis was suspected. Subsequent periorbital haemorrhage (Hällén and Rudin 1966) was thought to confirm the diagnosis despite the lack of histological confirmation. Post-mortem examination explained all the clinical symptoms.

In the second case the disease had for many years been thought to be a giant-cell tumour, though plasma cells in the bone marrow on one occasion and amyloid in a lymph node on another had suggested a different diagnosis. It was not until six years later when $\mathrm{M}$-components were discovered in the urine and two types of radiographic changes were distinguished that the diagnosis was reconsidered. A bone biopsy specimen and re-examination of the previous specimens revealed large masses of amyloid surrounded by giant cells as well as plasma cell infiltrates. Punched-out areas in the cranium and vertebrae were compatible with a diagnosis of myelomatous infiltration, but the complicated appearance of the changes in the ribs and upper arms fitted in less well with ordinary myelomatous destruction than with co-existing deposition of amyloid.

These two cases illustrate how difficult it is to demonstrate amyloid by skeletal radiography and to make a diagnosis of myelomatosis before the appearance of classical changes. In the first patient neither laboratory studies nor histological examination revealed any signs of myeloma to explain the formation of amyloid. Neither was there any chronic infection to explain the deposits; the extremely massive amyloid deposits seen in various organs after death appeared to have started in the vertebrae and to have produced radiographic changes resembling osteoporosis with progressive vertebral compression. This case is similar to the one published by Gerber (1934) with collapse of thoracic and lumbar vertebrae and massive deposits of amyloid in various organs. It is rather surprising that liver biopsy produced no evidence of amyloidosis. Re-examination of the biopsy specimen at necropsy, however, revealed small amounts of amyloid. Skeletal biopsy at an early stage of the disease in this patient would probably have resulted in the proper diagnosis. But even then it would not have been possible to modify the course of the disease.

The second case was one of myelomatosis with the formation of abnormal protein and the progressive development of radiographic features. Spontaneous fracture through a cyst 
of the left humerus, certainly secondary to local myeloma and amyloid deposits, brought the patient to hospital. After the disease had remained stationary for about three years the lymph nodes became involved with deposits of amyloid and plasma cells. Osteolysis of a cervical vertebra supervened. During the years following, the disease progressed with typical foci in the cranium and vertebrae and with atypical remodelling of the ribs, compatible with co-existing amyloid deposits. From a histological point of view the case had several remarkable features. Though the tumour had been examined on several occasions at different departments its true nature had remained obscure. Amyloid associated with myeloma does not always stain positively for amyloid.

These cases stress the importance in obscure conditions with skeletal changes of making a thorough search for amyloid and, if found, of continuing the investigation for myeloma. In the first case neither laboratory studies nor necropsy findings suggested myeloma. In the second case it was gradually realised that myeloma was the cause of the condition and in this case it is hoped that adequate cytostatic therapy will ameliorate and retard the further course of the disease. One wonders whether some of the cases described in the literature as amyloid tumour are not also of this type but that the tissue obtained for examination was not representative because amyloid masses in large areas had completely replaced tumour tissue.

\section{SUMMARY}

Two cases of skeletal amyloidosis are described. In one the disease existed for many years, progressively destroying several vertebral bodies. There was no evidence of chronic infection, myelomatosis or cancer. In the other case myelomatosis was the primary disease but the first manifestation was a cystic tumour of the humerus. Not until several years later did typical bone lesions and Bence-Jones protein reveal the true nature of the disease.

\section{REFERENCES}

BONSDORFF, B. von (1933): Atypisk Amyloidos. Finska läkaresällskapets handlingar, 75, 447.

BüRGI, U. (1937): Úber einen Fall von solitärem Amyloidtumor des Scheitelbeins. Frankfurter Zeitschrift für Pathologie, 50, 410.

Dahlin, D. C., and Dockerty, M. B. (1950): Amyloid and Myeloma. American Journal of Pathology, $26,581$.

DüNNER, M. (1946): Plasmocytom des Manubrium sterni mit lokaler Amyloidbildung. Schweizerische medizinische Wochenschrift, 76, 1109.

Fadell, E. J., and Morris, H. C. (1964): Amyloidoma Presenting as a Primary Sternal Tumor. American Journal of Surgery, 108, 75.

Freund, E. (1930): Uber diffuses Myelom mit Amyloidtumoren. Frankfurter Zeitschrift für Pathologie, 40, 400.

Gerber, I. E. (1934): Amyloidosis of the Bone Marrow. Archives of Pathology, 17, 620.

HEDRÉN, G. (1907): Ein Amyloidtumor des Knochenmarkes. Zeitschrift für klinische Medizin, 63, 212.

Hällén, J., and Rudin, R. (1966): Peri-collagenous Amyloidosis. Acta medica Scandinavica, 179, 483.

Koletsky, S., and Stecher, R. M. (1939): Primary Systemic Amyloidosis. Archives of Pathology, $27,267$.

Lowell, D. M. (1967): Amyloid-Producing Plasmacytoma of the Pelvis. Archives of Surgery, 94, 899.

MANDL, J. (1924): Úber lokales Amyloid im Bereiche der Brustwirbelsäule. Virchows Archiv für pathologische Anatomie und Physiologie und für klinische Medizin, 253, 639.

Michelson, H. E., and LyNCH, F. W. (1934): Systemized Amyloidosis of the Skin and Muscles. Archives of Dermatology and Syphilology, 29, 805.

Pende, G., and Chiarioni, T. (1953): Revisione critica degli aspetti anatomoclinici della malattia plasmocitomatosa. Medicina (Parma), 3, 669.

Rosemblum, A. H., and Kirschbaum, J. D. (1936): Multiple Myelomas with Tumor-like Amyloidosis. Journal of the American Medical Association, 106, 988.

Schinz, H. R., BaensCh, W. E., Friedl, E., and Uehlinger, E. (1952): Lehrbuch der Röntgendiagnostik, I: 1, 922. Stuttgart: C. Thieme Verlag.

WALlgReN, A. (1920): Untersuchungen über die Myelomkrankheit. Upsala Läkareförenings Förhandlingar, 25, 113.

WOLPERT, I. (1920): Beitrag zur Kenntnis der metastasierenden Amyloid-tumoren. Virchows Archiv für pathologische Anatomie, 227, Beihefte 173.

VOL. 52 B, NO. 4, NOVEMBER 1970 